\title{
An Application of the Two-Factor Mixed Model Design in Educational Research
}

\author{
O.A NUGA \\ ${ }^{a,}$ Department of Physical Sciences/Applied Mathematics with Statistics Unit, Bells University of Technology, \\ Ota, Nigeria
}

Received: 31 March 2019; Accepted: 14 June 2019; Published: 08 November 2019

\begin{abstract}
As with any ANOVA, a repeated measure ANOVA tests the equality of means. However, a repeated measure ANOVA is used when all members of a random sample are measured under a number of different conditions. As the sample is exposed to each condition in turn, the measurement of the dependent variable is repeated. Using a standard ANOVA in this case is not appropriate because it fails to model the correlation between the repeated measures: the data violate the ANOVA assumption of independence. Some ANOVA designs combine repeated measures factors and independent group factors. These types of designs are called mixed-model ANOVA and they have a split plot structure since they involve a mixture of one between-groups factor and one within-subjects factor.

The work present an application of the mixed model factorial ANOVA, using scores obtained by 120 secondary school students in mathematics. The between group factor is the different categories of students (science, commercial humanities) with three levels while the within group factor is the three years spent in senior secondary School.

Index Terms: Sphericity, Factorial ANOVA, Split-plot Structure, Senior Secondary Students, Mathematics

(C) 2019 Published by MECS Publisher. Selection and/or peer review under responsibility of the Research Association of Modern Education and Computer Science
\end{abstract}

\section{Introduction}

Analysis of Variance (ANOVA) is the suitable statistical technique when investigating differences between groups having continuous measurement [1]. There are several forms of ANOVA that can be used depending on

* Corresponding author.

E-mail address: 
the goal of the research.

Between-Subjects ANOVA is useful when investigating differences between independent groups on a continuous level variable. The one-way ANOVA and factorial ANOVA are types of between-subject ANOVA. As an example one can be interested in investigating the differences between scores obtained by three classes of students based on their scores in mathematics. Within-Subjects ANOVA is used when the aim is to measure differences in a continuous level variable over time. It is associated with measuring a continuous variable from the same subject over time with the aim of evaluating differences within those same subjects.

Another name for within-subjects ANOVA is the repeated measure ANOVA. This technique can be applied to investigate differences in mathematics scores obtained over three years by students.

A combination of the between-subjects ANOVA and the within-subjects ANOVA usually called the mixedmodel ANOVA is a type of factorial ANOVA where the aim of the research is to examine changes in a continuous variable by group and over time. This work used the mixed model factorial ANOVA to examine changes in mathematics scores in the three years spent in senior secondary school among the three main categories (Sciences, Commercial and Humanities) preparatory to writing the Senior Secondary School Examination (SSCE). The study covered the scores of 40 senior secondary students each in the three categories.

\section{Literature Review}

Mathematics is a compulsory subject that every student must pass to gain admission into higher institutions in Nigeria irrespective of the desired course of study. Mathematics has been described as the pillar of all knowledge relevant to all disciplines [2]. The importance of the subject to scientists is vast because the subject allows scientists to communicate their ideas [3]. For a nation to continually produced scientists, technologists and engineers, then they must take the teaching and learning of mathematics very seriously [4]. Science, technology and mathematics education have been widely acclaimed to be the index of measuring the socioeconomic and political development of any nation [5]. Notwithstanding the relative significance, students' performance in the subject in West African Examination Council (WAEC) has remained constantly poor [6]. All efforts directed towards improving students' performances have yielded very little results [3]. Researchers have continued to carry out studies to determine the difficult concepts or topics that are contributing to these poor performances.

Investigation of concepts in geometry that students in Senior Secondary year two (SS2) in Ekiti State perceived as difficult to learn was carried out using a 23-item Questionnaire on Geometry Concepts in Mathematics Perceived Difficult. The results showed that 8 out of a total of 23 concepts were observed to be very difficult to learn. A number of works have also been done to determine the effect of gender on perceived difficult geometry concepts $[7,8,9]$. The findings from [7,9] suggested that male students have better understanding of difficult concepts in geometry than female students whereas [8] observed no differences between male and female students. Another research was conducted to examine difficult concepts in mathematics curriculum for Senior Secondary School Students. The work used a 31 item questionnaire to obtain data on the difficult concepts or topics in mathematics from 250 Senior Secondary year three (SS3) students. The findings of the study revealed that some mathematics topics such as longitude and latitude, mensuration, bearing were identified by students as difficult concept. Many of these studies employed the use of descriptive statistics and some inferential statistics such as one-way ANOVA and chi-square test to analyze data. This present study will consider the effect of the three years spent in senior secondary school on scores of different groups of students using the two factor mixed model ANOVA.

\section{Methodology}

The mixed-model (MM) factorial ANOVA is very useful methodology in educational research; this model can be used to examine the effect of several independent variables on a dependent variable [10]. It is more powerful test than the completely randomized ANOVA because it has a split-plot structure [10]. The two-factor 
MM ANOVA used for this research work consider a between-subjects factor with three levels and a withinsubjects factor also with three levels. The analyses and the ensuing interpretation of the MM factorial ANOVA is rather confounding giving the increasing assumptions linked with a more composite design as well as possibility of analysing and interpreting interaction effect.

The model as given by [11] is shown below

$Y_{i j k}=\mu_{\ldots}+\rho_{i(j)}+\alpha_{j}+\beta_{k}+(\alpha \beta)_{j k}+\varepsilon_{i j k}$

$\mu \ldots=$ Overall mean

$\rho_{i(j)}$ the random subject effect which is independent $N\left(0, \sigma_{\rho}{ }^{2}\right)$

$\alpha_{j}$ the constant class effect subject to $\sum \alpha_{j}=0$

$\beta_{k}$ the fixed class effect subjects to $\sum \beta_{k}=0$

$\sum_{j}(\alpha \beta)_{j k}=0$ for all $\mathrm{k}$ and $\sum_{k}(\alpha \beta)_{j k}=0$ for all $\mathrm{j}$

$\varepsilon_{i j k}$ are independent $N\left(0, \sigma_{\varepsilon}^{2}\right)$

The data layout for two-factor MM ANOVA for the work is shown on table 1

Table 1. Layout for MM factorial Design

\begin{tabular}{|c|c|c|c|c|}
\hline \multicolumn{4}{|c|}{$\operatorname{YEAR}(\mathrm{A})$} & \multirow[b]{2}{*}{ Year 3} \\
\hline CLASSES(B) & & Year 1 & Year 2 & \\
\hline \multirow{4}{*}{ Science } & 1 & $y_{111}$ & $y_{112}$ & $y_{113}$ \\
\hline & 2 & $y_{112}$ & $y_{212}$ & $y_{213}$ \\
\hline & : & & : & : \\
\hline & 40 & $y_{r_{1} 11}$ & $y_{r_{1} 12}$ & $y_{r_{1} 13}$ \\
\hline \multirow{4}{*}{ Commercial } & 1 & & $y_{122}$ & $y_{123}$ \\
\hline & 2 & $y_{221}$ & $y_{222}$ & $y_{223}$ \\
\hline & : & & : & : \\
\hline & 40 & $y_{r_{1} 21}$ & $y_{r_{1} 22}$ & $y_{r_{r_{1} 23}}$ \\
\hline \multirow{4}{*}{ Humanities } & 1 & $y_{131}$ & $y_{132}$ & $y_{133}$ \\
\hline & 2 & $y_{231}$ & $y_{232}$ & $y_{233}$ \\
\hline & $:$ & & & : \\
\hline & 40 & $y_{r_{1} 31}$ & $y_{r_{1} 32}$ & $y_{r_{3} 33}$ \\
\hline
\end{tabular}


$y_{i j}=\left[y_{i j 1}, y_{i j 2}, \ldots . y_{i j k}\right] \square N(\mu, V)$ denote the vector observation of the $i^{t h}$ subject within the $j^{\text {th }}$ class for $i=1,2, \ldots . ., r \quad j=1,2, \ldots ., a k=1,2, \ldots ., b$ and $V=\sigma_{\rho}^{2} I+\sigma_{e}^{2}$.

In this work $r=40, b=3, a=3$.

Assumptions for making inference back to the population play an important role in mixed model design. Because there are both between and within subject's designs, there are assumptions associated with each.

\subsection{Assumptions for Between-Subjects Factor (Classes)}

1) Scores are randomly and independently distributed in the population

2) Homogeneity of variance: There is equality of variance in the populations from which scores are selected.

3) The population distribution from which scores are taken is normal.

\subsection{Assumptions for Within-Subjects Factor (Year)}

1) Scores are independently and normally distributed in the population

2) Sphericity: The variances of the difference between all pairs of levels of the within-subjects factor are equal according to [12].

3) Equal variance-covariance matrices: in the presence of a between subject factor (B) evaluating the effects of the factor $(\mathrm{A})$ and the interaction effects $\mathrm{A} \times \mathrm{B}$ also requires that the variance-covariance matrices at each level of factor $\mathrm{B}$ be identical to each other in the population according to $[13,14]$.

Assumptions 2 and 3 have been together referred to as multi-sample sphericity by Keppel [12]. The test of equal covariance matrices at every level of factor B is absolutely necessary because testing for sphercity requires that the covariance matrices are pooled into one. The violation of the assumption has effect on the power of the test.

Violations of the sphericity assumption may result in an increase in the probability of Type I error [12]. This error indicates that the researcher could make the wrong decision and conclusion about the null hypothesis. It was pointed out that sphericity is likely to be violated in many applications and adjusted statistics should be used if the assumption of sphericity is violated [14]. These adjustments are made to the degree of freedom using correction alternatives developed by $[15,16]$.

The Analysis of Variance (ANOVA) table shown on table 2 is used to summarize the following F-statistics for testing for group differences, differences in condition and group $\times$ conditions, respectively:

$$
\begin{aligned}
& F_{g}=\frac{Q_{1} /(a-1)}{Q_{e 1} / a(r-1)} \square F(a-1), a(r-1) \\
& F_{c}=\frac{Q_{2} /(b-1)}{Q_{e 2} / a(r-1)(b-1)} \square F[(b-1), a(r-1)(b-1)] \\
& F_{g c}=\frac{Q_{3} /(a-1)(b-1)}{Q_{e 2} / a(r-1)(b-1)} \square F[(a-1)(b-1), a(r-1)(b-1)]
\end{aligned}
$$


Table 2. Two-factor MM ANOVA Table

\begin{tabular}{|lcl|}
\hline Source of Variation & DF & Sum of Squares \\
\hline Between Groups & $a-1$ & $Q_{1}=a \sum_{I} r_{J}\left(\bar{y}_{. j .}-\bar{y}_{\ldots . . .}\right)^{2}$ \\
\hline $\begin{array}{l}\text { Subject within-group } \\
\text { (within-error 1) }\end{array}$ & $a(r-1)$ & $Q_{e 1}=b \sum_{i} \sum_{j}\left(\bar{y}_{i j}-\bar{y}_{. j .}\right)^{2}$ \\
\hline Between conditions & $b-1$ & $Q_{2}=a r \sum_{k}\left(\bar{y}_{. . k}-\bar{y}_{\ldots . . .}\right)^{2}$ \\
\hline Group $\times$ Condition & $(a-1)(b-1)$ & $Q_{3}=\sum_{i} \sum_{k}\left(\bar{y}_{. j k}-\bar{y}_{. . k}-\bar{y}_{. j .}+\bar{y}_{\ldots . . .}\right)^{2}$ \\
\hline $\begin{array}{l}\text { Subjects } \times \text { Conditions } \\
\text { (within-error 2) }\end{array}$ & $a(r-1)(b-1)$ & $Q_{e 2}=\sum_{i} \sum_{j} \sum_{k}\left(\bar{y}_{i j k}-\bar{y}_{. j k}-\bar{y}_{i j .}+\bar{y}_{. j .}\right)^{2}$ \\
\hline Total & $a b r-1$ & $Q_{t}=\sum_{i j k}\left(\bar{y}_{i j k}-\bar{y}_{. . .}\right)^{2}$ \\
\hline
\end{tabular}

\subsection{Error Terms}

There are two different error term in the ANOVA table one for the between subject factor (groups) represented by another for the within subject factor (condition).Error term for the between subject factor represent the same estimate of error as in a one way ANOVA .i.e. an average of the within group variances across groups.

For the within subject factor the error is not due to differences between subject, because the same subjects perform under different levels. The error term used reflect the inconsistency with which the same subjects perform under different condition. For the within-subject in the mixed model design, the error term used for evaluating differences is the subject by treatment interaction at each level of the between-subject factor; the error term is the average of each subjects $\times$ condition interaction at the different levels of factor group.

\subsection{Test of Hypotheses}

The first hypothesis tested in a mixed model design is the hypothesis of interaction, because the acceptance or rejection of the hypothesis may affect how the main effect for factor A (repeated measure factor) is tested. Test of the main effects may not be appropriate when there is interaction according to [12]; it is recommended that we divide the design to a single factor design. Analyses of this sort are called simple effects e.g. this is equivalent to a single factor repeated measure design; this can be achieved by evaluating an omnibus $\mathrm{F}$ statistics.

To avoid duplicate testing, a simple contrast for our simple effects-contrast between the cells mean was suggested by [10] e.g. a simple contrast for this project work will be, is there a difference in year one and the 
year two mathematics scores for students in the science class. Simple contrasts for the simple effects of factor A at every level of B can be calculated.

The assumption of sphericity plays an important role when contrasts are considered; it is recommended that if the assumption is violated, the pooled error term $Q_{e 2}$ should not be used to compute simple contrasts [10]. If the assumption is tenable, the error term $Q_{e 2}$ on the analysis of variance table above can be used. When the assumptions are not met, separate error terms are used for each contrast [15]; in this case the dependents sample t-test is a viable alternative for simple contrasts. Whenever either the assumption of sphericity or equal covariance matrices is violated separate error term should be used for each contrast [12]. If the assumption of homogeneity of variance is met for factor B, turkey (HSD) test will be used to test which sample means are significantly different from others.

\section{Presentation of Result}

The results of the assumptions underlying a univariate model for repeated measure (mauchly test of sphericity and box test of equal variance covariance matrices) are presented on Table 3 and Table 4 . The test of the main effect of factor A (changes in scores overtime) and the main effect of factor B (differences in the scores between classes) are shown on Table 5 and 6 respectively. The paired sample t-tests of simple contrast are shown on Table 7 to Table 9.

Table 3. Mauchly Test of Sphericity

\begin{tabular}{|l|l|l|l|l|l|}
\hline & Mauchly & Approx Chi-square & Df & p-value & Epsilon \\
\hline Within subject Effect & & & & & Greenhouse-Geisser \\
\hline Math score & 0.908 & 11.219 & 2 & 0.004 & .915 \\
\hline
\end{tabular}

Table 4. Box Test of Homogeneity of Covariance Matrices

\begin{tabular}{|l|l|l|l|l|}
\hline Box's M & F & Df1 & Df2 & P-value \\
\hline 9.816 & 0.788 & 12 & 66339 & 0.664 \\
\hline
\end{tabular}

Table 5. Test of Within-Subject Effects (Green-House-Geisser)

\begin{tabular}{|l|l|l|l|l|l|}
\hline Source & Sum of Squares & Df & Mean Square & F & P-value \\
\hline Year & 1220.006 & 1.831 & 666.235 & 7.545 & 0.001 \\
\hline Year $\times$ Class & 1568.194 & 3.662 & 428.189 & 4.849 & 0.001 \\
\hline Error & 18919.8 & 214.250 & 88.307 & & \\
\hline
\end{tabular}

Table 6. Test of Between Subjects-Effects

\begin{tabular}{|l|l|l|l|l|l|}
\hline Source & Sum of Square & Df & Mean Square & F & P-value \\
\hline Classes & 315.669 & 2 & 157.834 & 4.085 & 0.019 \\
\hline Error & 4250.150 & 117 & 38.634 & & \\
\hline
\end{tabular}


Table 7. Multiple Comparisons of Means (Turkey HSD)

\begin{tabular}{|l|l|l|l|l|}
\hline Class (I) & Class (J) & Mean Difference (I-J) & Standard Error & P-value \\
\hline Science & Commercial & 0.425 & 1.3899 & 0.950 \\
\hline Science & Humanity & 3.6333 & 1.3899 & 0.027 \\
\hline Commercial & Humanity & 3.2083 & 1.3899 & 0.059 \\
\hline
\end{tabular}

Table 8. Paired Sample t-test (Science Class)

\begin{tabular}{|l|l|l|l|}
\hline Contrast & T & Df & Sig (2tailed) \\
\hline Year 1 -Year 2 & -1.064 & 39 & .294 \\
\hline Year 2 -Year 3 & 0.169 & 39 & 0.869 \\
\hline
\end{tabular}

Table 9. Paired Sample t - test (Commercial Class)

\begin{tabular}{|l|l|l|l|}
\hline Contrast & T & Df & Sig (2tailed) \\
\hline Year 1 - Year 2 & 0.439 & 39 & 0.663 \\
\hline Year 2 - Year 3 & -2.603 & 39 & 0.013 \\
\hline
\end{tabular}

Table 10. Paired Sample $\mathrm{t}-$ test (Humanity Class)

\begin{tabular}{|l|l|l|l|}
\hline Contrast & T & Df & Sig (2tailed) \\
\hline Year 1 -Year 2 & 4.12 & 39 & 0.000 \\
\hline Year 2 - Year 3 & -4.188 & 39 & 0.000 \\
\hline
\end{tabular}

\section{Discussion of Results}

The result of the test of the sphericity assumption as shown on table 3 indicates that the variances of the difference between all pairs of levels of the within-subjects factor are not equal. A p-value $=0.004$ point to a violation of the sphericity assumption. The green house epsilon value of 0.915 was used to make adjustments to the degree of freedom of the F-test of within- subject effect on table 5. The test of the assumption of homogeneity of covariance matrices presented on table 2 shows no significance ( $\mathrm{p}$-value $=0.664$ ), suggesting that the population variance-covariance matrices at each level of factor B (classes) are equal.

As the sphericity assumption has been violated, the adjustment developed by Greenhouse and Geisser was used to test for the main effect of factor A (year) and its interaction with the between subjects factor B (classes). Since the test of the interaction effect is the first hypothesis to be considered in the two factor MM design [12]; the first hypothesis considered on table 5 was the interaction effect. The result showed that there is an interaction effect between the two factors therefore result of the main-effect of factor A (year) may not be appropriate even though it showed significance.

The test of between-subjects effect test on table 6 showed significance with a p-value of 0.0019 ; therefore Turkey (HSD) test was employed to do pair-wise comparison of mean as presented on table 7 . The result of the Turkey (HSD) test showed no difference in the mathematics scores of the science class and commercial class with a mean difference of 0.425 and a p-value of 0.950 . This p-value indicates that the mathematics scores of science class and commercial class are almost the same over the three years. The mean difference of 3.6333 and a p-value of 0.027 suggest that the mathematics scores of science class are significantly better than that of 
the humanity students at a significant level of 5\%. The results also showed that mathematics scores of commercial class is virtually better than that of humanity class $(\mathrm{p}$-value $=0.059)$ over the three years

The dependent sample t-test (or paired sample t-test) was used to construct simple contrasts. The results presented on table 8 to table 10 revealed that the mathematics score of commercial group doubled that of over the three years whereas the mathematics score of science and humanity group did not change over the three years.

\section{Summary and Conclusion}

A mixed model factorial ANOVA has been used to analyze the results in mathematics of different classes of students in a senior secondary school in Abeokuta, Ogun state. Some previous works on the investigation of difficult topics in senior secondary mathematics as observed by students were reviewed. These identified topics which are usually taught at SS2 and SS3 could have an effect on performances of senior secondary students in mathematics. This work therefore used the mixed model factorial ANOVA to examine changes in mathematics scores in the three years spent in senior secondary school among the three main categories (Sciences, Commercial and Humanities) preparatory to writing the Senior Secondary School Examination (SSCE). The results of the descriptive statistics of the average score obtained over 3 years showed science students with the highest percentage of $55.09 \%$, the commercial students had $54.6 \%$ and the humanitiy students had $51.4 \%$. The results of the descriptive statistics also showed that the scores obtained in year three by the different categories of students was the highest with $55.96 \%$. The inferential test conducted on the between-subject factor showed differences in mathematics scores for the different categories of students while appropriate significant test conducted on the within-subject showed changes in the score obtained over the three years by humanity and commercial student.

These results allow the following conclusions to be made

- Categories of students have effect on mathematics scores as the humanity group scored had lower scores than the other groups.

- Humanity group and Science group mathematics scores did not improve overtime.

- The mathematics score of humanity group is lowest.

- The average mathematics scores of each group is equivalent to a credit pass.

Although the average mathematics score of science and commercial groups are higher than the humanity group, it is recommended that any effort geared towards mathematics improvement should not depend on the groups to which the students belong as the score for all the group is equivalent to a credit pass in the Senior School Certificate Examination.

\section{References}

[1] Tabachnick, B. G., \& Fidell, L.S. Using Multivariate Statistics (6th ed.). Boston, MA Pearson. 2013.

[2] Ayinla, J. O. Effects of Teachers Instructional Strategy Pattern on Senior School Students' Performance in Mathematics Word Problem in Ondo, Nigeria 2011. Unpublished M. Ed. Thesis, University of Ilorin, Ilorin, Nigeria, 2011.

[3] Fabiyi, T.R. Geometry Concepts in Mathematics Perceived Difficult to Learn by Senior Secondary School Students in Ekiti State, Nigeria. IOSR Journal of Research \& Method in Education. 2017; 7(1), 83-90.

[4] Adegun, I. K. and Adegun, B. O. Students and Teachers' Views of Difficult Areas in Mathematics Syllabus: Basic Requirement for Science and Engineering Education. Journal of Education and Practice. 2013; 4(12), 235-243.

[5] Betiku, O. F. Causes of Mass Failure in Mathematics Examinations among Students. A commissioned Paper Presented at Government Secondary School, Karu, Abuja, 2000. 
[6] National Mathematical Centre, NMC, Abuja, Mathematics improvement programme. Retrieved on 26th July, 2013 from www.nmcabuja.org/mathematics improvement programmes.html, 2009.

[7] Uduosoro, U. J. Perceived and Actual Learning Difficulties of Students in Secondary School Mathematics. International Multidisciplinary Journal, Ethiopia, 5 (5), 2011, 357-366.

[8] Gbodi, B. E. and Olaleye, A. M. Effects of Videotaped Instruction on Learning of Integrated Science. Journal of Research in Curriculum and Teaching. 2006; 1(1), 10-19.

[9] Baharvand, M. A comparison of the Effectiveness of Computer-assisted Instruction versus Traditional approach to Teaching Geometry. Unpublished master's thesis, California State University, USA, 2001.

[10] Mills Jamie D. Teaching the Mixed Model Design: A flow Chart to Facilitate Understanding. Education. 2005; 125:3.

[11]Kutner, M.H., Nachtsheim, C.J., Neter, J. and Li, W. Applied Linear Statistical Models. 5th Edition, McGraw-Hill, Irwin, New York. 2005; 1141-1142.

[12]Keppel G. Design and Analysis: A researchers Handbook (3rd Edition)" Upper Saddle River, N.J. Prentice Hall, 1991; 48-50.

[13]Kesselman, H.T, Algina J., \&Kowalchuk, R.K. A comparison of Data Analysis Strategies for Testing Omnibus Effects in Higher-Order Repeated Measure Design. Multivariate Behavioral Research. 2002; 37(3) 331-357.

[14]Maxwell, S.E. and Delaney, H.D. Designing Experiment and Analyzing Data: A Model Comparison Perspective. Wardsworth, Belmont, California, 1990; 60-62.

[15]Greenhouse, S.W and Geisser S. On the Methods in the analysis of Profile Data. Psycometrika. 1959; 24: 95-112.

[16]Huynh, H. and Feldt L.S. Conditions under which the Mean Square Ratio in Repeated Measure Designs have Exact F-distributions. Journal of America Statistical Association. 1970; 85: 152-1589.

[17] Lomax, R.G. An Introduction to Statistical Concepts for Education and Behavioral Sciences. Mahwah, NJ, Lawrence Erlbaum Associates, 2002; 103-105.

\section{Authors' Profiles}

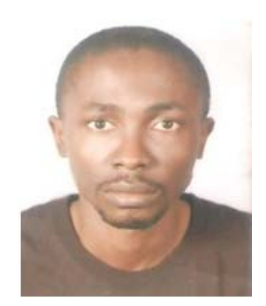

Nuga O.A has a PhD in Statistics and has been teaching Statistics in the University for more than 10 years. His research interest is in Design and Analysis of Experiments.

How to cite this paper: O.A NUGA," An Application of the Two-Factor Mixed Model Design in Educational Research", International Journal of Mathematical Sciences and Computing(IJMSC), Vol.5, No.4, pp.24-32, 2019. DOI: $10.5815 / \mathrm{ijmsc} .2019 .04 .03$ 